\title{
Secure Cloud Computing with Third Party Auditing: A Survey
}

\author{
Laxmikant Mishra \\ M.Tech Research Scholar \\ Computer Science \\ Gyan Ganga Institute of Technology \& \\ Management Bhopal
}

\author{
Amit Kumar Sharma \\ Assistant Professor \\ Computer Science \\ Gyan Ganga Institute of Technology \& \\ Management Bhopal
}

\begin{abstract}
Cloud computing based technology and their impact is growing now a day. Cloud computing is used in all the area of Business, Education, Social Impact and data miner. The growing demand is because of the on demand service and pay per basis used somehow in the unlimited form. But the uses enhance the risk of data trapping and forgery. As the services are sharing within different cloud users and the accessibility are also different. So the security issues in cloud computing environment are a major concern. As the users totally rely on the cloud vendors, so there is a need of data protection and the data control from the cloud users. So the main aim of my paper finds the advancement in the related previous technology and the gaps. Based on our study some future enhancements have been suggested.
\end{abstract}

\section{Keywords}

Cloud Computing, Virtualization, Optimization, Security.

\section{INTRODUCTION}

Cloud computing provide on demand resources based on pool of resources available by the cloud providers [1] [2] [3]. From the aspect of traditional computing the advantages of cloud computing are: Effective Cost, Device Independency, on demand service and scalability [4] [5]. But the security concerns are the major key aspects in the future cloud computing era. There are several security majors are suggested in [6], [7], [8], [9],[10],[5].Virtualization, high performance computing are also the greater facility aspects of cloud computing. But to achieve the performance on the parallel system and maintaining the integrity is tough [11]. All the above work shows the inclusion of efforts made to design solutions that are used to fulfill various requirements like: efficiency, verification, unbounded use of queries and irretrievability of data, etc. The two categories are private auditability and public auditability Private and Public auditability are the two categories of the verifier.[5]. Although schemes with private auditability can achieve the schemes efficiently, but it is challenging situation if the data is storing privately [5]. Virtualization is the key feature of cloud computing by which data sharing is possible between different machines of virtual existence from the data center [12]. Virtualization enables the resource migrations [9] of virtual machines which is stable and take in part as the virtual machine parameters to the consumers and balance the load across physical servers in the data centers [12].

In today's age several companies are in the great position for the cloud provider. The list of the cloud providers are [13]:

- Google- It is a provider of private cloud. It provide the services like email, document applications, data translation services, maps, web analytics, etc.[13].
- Microsoft- It has SharePoint service that mainly provides the services in the area of content and business intelligence. For this they provide tools to be moved into the cloud area [13].

- Salesforce.com- It runs the cloud application for its customers in a cloud. The main products are Force.com and Vmforce.com. It provides platforms to build customized cloud services [13]. But the security concerns are uncovered.

The cloud computing framework relies on the layers for data transportation. Cloud computing services are mainly divided into two parts cloud computing services and the deployment model. The three main service layers that comprise the cloud computing architecture based on which the on demand service will be provided [14]. According to [14] Software as a Service (SaaS) has transformed desktop-based software applications into online software products that can be used worldwide. Salesforce.com provides a customer relationship management (CRM) software for businesses and clients interactions [14]. According to [14] Platform as a Service (PaaS) is an environment for Cloud Computing Security Management for developing and building applications for different environments. According to Infrastructure as a Service (IaaS) mostly involves virtualization environments as purchased services rather than physical or dedicated computer equipment. The services layers are shown in figure 1 .

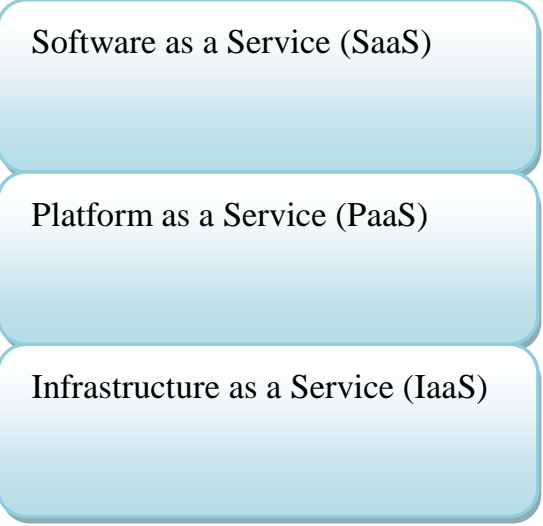

Figure 1: Types of Service Models in Cloud Computing [13]

In the traditional way of computing the resources are purchased locally which are sometimes higher in cost and not affordable. This limits the ways in which a user could interact with the software in that the software was only available and accessible for the original workstation [14]. But now by the use of cloud computing the Software as a Service model has transformed this methodology in such a way that software can be purchased for use over the Internet [14]. Instead of 
purchasing software it is directly hosted in the cloud [14]. The main benefit of this type of system is there is no need of powerful work station as the user location but on demand resources/software can share it with rent. So if it is integrated with the security regimes it becomes powerful. The data is deployed based on three categories. First is public second is private and third is hybrid. In public cloud the resources are used in general public. The list of public cloud providers are IBM's Blue Cloud, Elastic Compute Cloud (EC2), Sun Cloud, Windows Azure Services Platform and Google AppEngine. It is not sell as a service and it is costly. Portion of the public cloud can be migrated or clubbed as a hybrid cloud but it contains the feature of both deployment model.

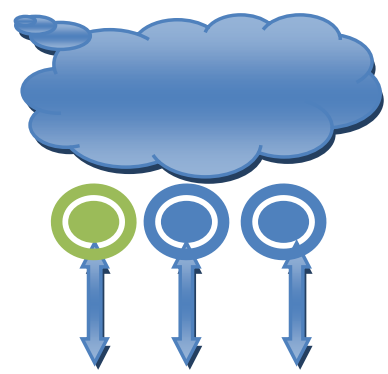

(a)

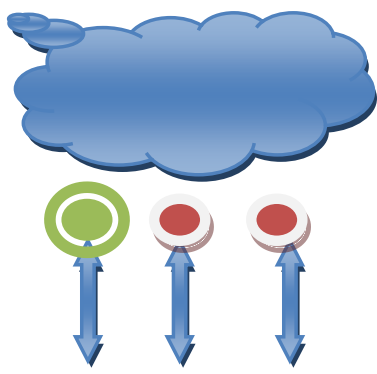

(b)

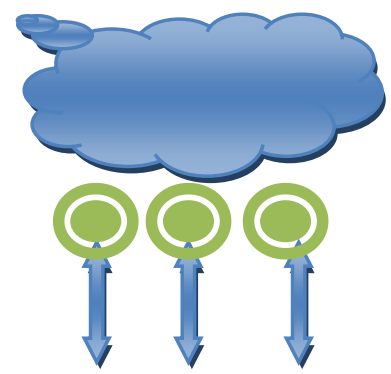

(c)

Figure 2: a) Public Cloud, b) Private Cloud, c) Hybrid Cloud

\section{LITERATURE SURVEY}

In 2010, Wang et al. [15] for solving the privacy preserving role of cloud a private match and min-attribute generalization approach was suggested. Privacy indexing is also suggested in the internet. In 2010, Wang et al. [16] suggest a method for cloud computing security. They named this method as private face recognition method. It has three components: user part provides face images; cloud initialization part has a face subspace and templates database; cloud private matching identification part contains the core algorithm of the method, comparing two encrypted numbers under double-encrypted conditions. Their results shows that the method can ensure that cloud neither know user's real face data, nor the face private matching identification result, to make user's face data secure. In 2011, Zheng et al. [17] provides a comparison between private cloud and public cloud. Based on their study they suggest the theoretical reference to build the private cloud computing. In 2011, Li et al. [18] presented a study using online Personal Health Record (PHR), it shows the necessity of authorization capability which reduces the privacy exposure find from the search results, and establishes a scalable framework for Authorized Private Keyword Search (APKS) over encrypted cloud data. In 2011, Yang et al. [19] suggest Storage-as-a-service is an important component of cloud computing. Authors suggest the searching capability based on private data over the encryption standard. It also provides multi-user searchable encryption, for the single-user setting. A practical multi-user searchable encryption scheme was proposed to taking the advantage consideration. In 2011, Wang et al. [20] discussed the problem of ensuring the integrity of data storage. This task is allowing a third party auditor (TPA), based on the cloud client, to judje the integrity of the data stored in the cloud. It holds good in achieving economies scale. In 2012, Naqvi et al. [21] suggest a testing way to find the scalability and heterogeneity of federated Cloud security services. The goal is to impact the security functions under several operating conditions. The results based on the above scenario will help in different businesses scenario to identify the security architecture which fit in requirements. In 2012, Tianfield et al. [22] analyzes the cloud security requirements based on various parameters like integrity, confidentiality, trust, availability and compliance. In 2012, Abuhussein et al. [23] suggest volume shortage in Healthcare, education and business industry and suggest cloud computing infrastructure. But the data to the cloud and the data shifting process in not controlled at the users end. The security and privacy of the customer's is an important issue. So attributes which are responsible security and privacy are analyzed. Security provisions can make a better cloud vision in future. In 2012, Liu et al. [24] also discussed the security problem of cloud computing. Computing Systems are analyzed based on computing concepts and characters. Cloud computing security problem are not solved by single security. So traditional and latest technologies can be a better combination to solve this issue. In 2013, Pant et al. [25] discusses about security and compliance assessment with the cloud computation time and adoption mechanism. In 2013, meng et al. [26] discusses security issues, data transmission security, storage capacity and management They suggest that the universal data management may affect cloud security strategies and it may be evocated long-term development direction. In 2013, Yang et al. [27] suggested Trusted Cloud Computing Platform (TCCP) for remote attestation which provides better security for tenant. The different authentication policies, such as user password checking, image hash verification and chain measurement are the different levels of security should be adopted.

\section{PROBLEM DOMAIN}

Third party auditing and security is the greater concern today. There are few areas which are still unattended in cloud computing security such as auditing, side channels and migration of data from one cloud to another [33]. Cadence has evermore been on immutable make believe and corrupt assail but the pretence of service has not been considered. The check tick off on protean organize with cherish to respect to overcast computing is another open research issue. On touching celebration, know-how and restrictive computational intellect 
creates obstacle in conduct oneself to provide best performance to mobile user. This handbill to pieces provides percipient view of cloud computing security issues.

Brave and violent base systems are increasingly reliant on cloud computing applications in order to provide elements of functionality and achieve the associated missions. Leaning towards the in conformity and misemploy more these applications, they eat be cheerful to failures and attacks detecting, move wink at through, recovering immigrant, and reconfiguring in response to such issues. Pliancy is break the ice as the industriousness of uphold government stroll last analysis definitely be veracious when facing swings. These changes could be anything from unanticipated failures, intrusions, accidents, and/or increased albatross. Connect of the small of brisk such percipient systems in the depressing is on-demand equipping attributes to make do nigh load and in finical to handle the highest expected load. This typically leads to "dormant", brand-new affirmative drift we utilize to increase security and reliability.

\section{ANALYSIS}

The overall analysis in all the aspects are shown in table 1.

Table 1: Comparative Analysis

\begin{tabular}{|c|c|c|c|c|}
\hline S.no & Authors & Year & Work & Gap \\
\hline 1 & Vijay et al.[28] & 2012 & $\begin{array}{l}\text { Authors considered an } \\
\text { architecture where different } \\
\text { services are hosted on the } \\
\text { cloud infrastructure by } \\
\text { multiple cloud customers } \\
\text { (tenants). This model extends } \\
\text { the node controller with the } \\
\text { functionality of the } \\
\text { Certification Authority to } \\
\text { certify the behavior of the } \\
\text { tenant virtual machines. }\end{array}$ & $\begin{array}{l}\text { Since the Node } \\
\text { Controller is aware } \\
\text { of the dynamic } \\
\text { changes to the } \\
\text { tenant virtual } \\
\text { machine, it can } \\
\text { ensure that the } \\
\text { certified properties } \\
\text { are satisfied by the } \\
\text { tenant virtual } \\
\text { machines. }\end{array}$ \\
\hline 2 & $\begin{array}{l}\text { Abdullah Abuhussein } \\
\text { et al. [23] }\end{array}$ & 2012 & $\begin{array}{l}\text { Authors identify and } \\
\text { categorize a list of attributes } \\
\text { which reflect the various } \\
\text { aspects of cloud security and } \\
\text { privacy. }\end{array}$ & $\begin{array}{l}\text { Quantifying metrix } \\
\text { for promoting the } \\
\text { attributes is missing. }\end{array}$ \\
\hline 3 & Huaglory[22] & 2012 & $\begin{array}{l}\text { Presents a comprehensive } \\
\text { study on the challenges and } \\
\text { issues of security in cloud } \\
\text { computing. }\end{array}$ & $\begin{array}{l}\text { Security } \\
\text { authentication } \\
\text { mechanism are not } \\
\text { elaborated properly. }\end{array}$ \\
\hline 4 & Irina et al. [29] & 2012 & $\begin{array}{l}\text { They suggest some of the } \\
\text { key benefits and the major } \\
\text { drawbacks that come around } \\
\text { with swapping out services } \\
\text { and infrastructure to a public } \\
\text { cloud. Based on these } \\
\text { benefits and drawbacks, } \\
\text { K.O. (knock-out) criteria } \\
\text { will be identified, which can } \\
\text { be seen as the minimum } \\
\text { basis for secure cloud } \\
\text { Environment. }\end{array}$ & $\begin{array}{l}\text { Suggested } \\
\text { techniques should } \\
\text { be implemted. }\end{array}$ \\
\hline 5 & Mehdi et al. [30] & 2013 & $\begin{array}{l}\text { Authors purpose is to } \\
\text { concentrate on cloud data } \\
\text { storage security and to } \\
\text { manage the user's data in } \\
\text { the cloud by Implementation } \\
\text { of kerberos authentication } \\
\text { Service. }\end{array}$ & $\begin{array}{l}\text { Other standard } \\
\text { encryption } \\
\text { techniques can also } \\
\text { be used. }\end{array}$ \\
\hline 6 & $\begin{array}{l}\text { Liu Xiao-hui et al. } \\
\text { [31] }\end{array}$ & 2013 & $\begin{array}{l}\text { Authors introduced cloud } \\
\text { development status, and } \\
\text { analyzed the security } \\
\text { problems. }\end{array}$ & $\begin{array}{l}\text { The security } \\
\text { problem has become } \\
\text { a focus }\end{array}$ \\
\hline 7 & $\begin{array}{ll}\text { Azzedine } & \text { Benameur } \\
\text { et al. [32] } & \end{array}$ & 2013 & $\begin{array}{l}\text { Authors present an approach } \\
\text { to leverage the elasticity and } \\
\text { on-demand provisioning } \\
\text { features of the cloud to } \\
\text { improve resilience to } \\
\text { availability concerns and } \\
\text { common attacks. }\end{array}$ & $\begin{array}{lr}\text { Need of } & \text { supporting } \\
\text { different } & \text { file } \\
\text { formats. }\end{array}$ \\
\hline
\end{tabular}




\begin{tabular}{|c|c|c|c|c|}
\hline 8 & Issa et al. [33] & 2013 & $\begin{array}{l}\text { Authors provide } \\
\text { comprehensive study of } \\
\text { cloud computing security } \\
\text { that includes } \\
\text { classification of known } \\
\text { security threats and the } \\
\text { state-of-the-art } \\
\text { practices in the endeavor to } \\
\text { calibrate these threats. They } \\
\text { also provides the } \\
\text { dependency level within } \\
\text { classification and provides a } \\
\text { solution in form of } \\
\text { preventive actions rather } \\
\text { than proactive actions. }\end{array}$ & $\begin{array}{l}\text { Cloud computing } \\
\text { security such as } \\
\text { auditing, side } \\
\text { channels and } \\
\text { migration of data } \\
\text { from one cloud to } \\
\text { another. } \\
\text { Emphasis has } \\
\text { always been on fast } \\
\text { performance and } \\
\text { low cost } \\
\text { but the quality of } \\
\text { service has not been } \\
\text { considered. }\end{array}$ \\
\hline 9 & $\begin{array}{l}\text { Ching-Nung Yang et } \\
\text { al. [34] }\end{array}$ & 2013 & $\begin{array}{l}\text { Authors deal with cloud } \\
\text { security services including } \\
\text { key agreement and } \\
\text { authentication. By using } \\
\text { Elliptic Curve Diffie- } \\
\text { Hellman (ECDH) } \\
\text { and symmetric bivariate } \\
\text { polynomial based secret } \\
\text { sharing, authors } \\
\text { design the secure cloud } \\
\text { computing (SCC). }\end{array}$ & $\begin{array}{l}\text { It can be extended } \\
\text { to multi-layer } \\
\text { security scheme. }\end{array}$ \\
\hline 10 & Qian Wang et al. [35] & 2013 & $\begin{array}{l}\text { This work studies } \\
\text { the problem of ensuring the } \\
\text { integrity of data storage in } \\
\text { Cloud Computing. In } \\
\text { particular, we consider the } \\
\text { task of allowing a third party } \\
\text { auditor (TPA), on behalf of } \\
\text { the cloud client, to verify the } \\
\text { integrity of the dynamic data } \\
\text { stored in the cloud. }\end{array}$ & $\begin{array}{l}\text { Other standard } \\
\text { encryption } \\
\text { techniques can also } \\
\text { be used to enhance } \\
\text { the security. }\end{array}$ \\
\hline
\end{tabular}

\section{CONCLUSION AND FUTURE WORK}

Security is major concern today in the cloud computing environment. Third party auditing and external security services are needed due to increasing demand of the cloud computing. So our paper main aim to study and analysis the aspects of cloud computing security. Future suggestions are following:

1) Hybridization of virtualization and Optimization may be used.

2) Trusted framework can be developed by using RSA and MD5 Algorithm [5].

3) Data mining task can be computed in cloud environment for proper data classification and categorization [36].

4) Provide secure framework for providing mobile cloud computing making data access and handling mechanism by data mining [37].

5) Data Security can be provided by RC4, RC5 etc.[38].

6) Strong user authentication is also a good chice[39].

\section{REFERENCES}

[1] M. Armbrust, A. Fox, R. Griffith, A. D. Joseph, R. H. Katz, A. Konwinski, G. Lee, D. A. Patterson, A. Rabkin, I. Stoica, and M. Zaharia, "Above the clouds: A berkeley view of cloud computing," University of California, Berkeley, Tech. Rep. UCB-EECS-2009-28, Feb 2009.

[2] Igor Ruiz-Agundez, Yoseba K. Penya and Pablo G. Bringas, "Cloud Computing Services Accounting", International Journal of Advanced Computer Research (IJACR), Volume 2, Number 2, June 2012.

[3] Ajey Singh, Maneesh Shrivastava, "Overview of Security issues in Cloud Computing", International Journal of Advanced Computer Research (IJACR) Volume 2,Number 1,March 2012.

[4] G. Ateniese, R. Burns, R. Curtmola, J. Herring, L. Kissner, Z. Peterson, and D. Song, "Provable Data Possession at Untrusted Stores," Proc. 14th ACM Conf. Computer and Comm. Security (CCS '07), pp. 598-609, 2007.

[5] Ashutosh Kumar Dubey, Animesh Kumar Dubey, Mayank Namdev, Shiv Shakti Shrivastava," Cloud-User Security Based on RSA and MD5 Algorithm for Resource Attestation and Sharing in Java Environment", CONSEG-2012. 
[6] A. Juels and B.S. Kaliski Jr., "Pors: Proofs of Retrievability for Large Files," Proc. 14th ACM Conf. Computer and Comm. Security (CCS '07), pp. 584-597, 2007.

[7] H. Shacham and B. Waters, "Compact Proofs of Retrievability," Proc. 14th Int'l Conf. Theory and Application of Cryptology and Information Security: Advances in Cryptology (ASIACRYPT '08), pp. 90-107, 2008 .

[8] K.D. Bowers, A. Juels, and A. Oprea, "Proofs of Retrievability: Theory and Implementation," Report 2008/175, Cryptology ePrint Archive, 2008.

[9] M. Naor and G.N. Rothblum, "The Complexity of Online Memory Checking," Proc. 46th Ann. IEEE Symp. Foundations of Computer Science (FOCS '05), pp. 573$584,2005$.

[10] Wei-Tek Tsai, Xin Sun, Janaka Balasooriya , "ServiceOriented Cloud Computing Architecture", 2010 Seventh International Conference on Information Technology.

[11] G K Patra, Nilotpal Chakraborty," Securing Cloud Infrastructure for High Performance Scientific Computations Using Cryptographic Techniques", International Journal of Advanced Computer Research (IJACR), Volume-4 Number-1 Issue-14 March-2014.

[12] Nilesh Pachorkar, Rajesh Ingle," Multi-dimensional Affinity Aware VM Placement Algorithm in Cloud Computing", International Journal of Advanced Computer Research (IJACR) Volume-3 Number-4 Issue13 December-2013.

[13] http://www.dialogic.com/ /media/products/docs/whitepa pers/12023-cloud-computing-wp.pdf

[14] Tschinkel, Brian. "Cloud Computing Security Understanding Risk Areas \& Management Techniques." (2011)

[15] Jian Wang and Jiajin Le," Based on Private Matching and Min-Attribute Generalization for Privacy Preserving in Cloud Computing", Sixth International Conference on Intelligent Information Hiding and Multimedia Signal Processing, 2010.

[16] Chenguang Wang, Huaizhi Yan," Study of Cloud Computing Security Based on Private Face Recognition",IEEE 2010.

[17] Ling Zheng, Yanxiang Hu,Chaoran Yang," Design and research on private cloud computing architecture to Support Smart Grid", Third International Conference on Intelligent Human-Machine Systems and Cybernetics, 2011

[18] Ming Li, Shucheng Yu, Ning Cao and Wenjing Lou," Authorized Private Keyword Search over Encrypted Data in Cloud Computing", 31st International Conference on Distributed Computing Systems, 2011.

[19] Yanjiang Yang," Towards Multi-User Private Keyword Search for Cloud Computing", IEEE 4th International Conference on Cloud Computing, 2011.

[20] Wang, Qian, Cong Wang, Kui Ren, Wenjing Lou, and Jin Li. "Enabling public auditability and data dynamics for storage security in cloud computing." Parallel and Distributed Systems, IEEE Transactions on 22, no. 5 (2011): 847-859.
[21] Naqvi, S.; Michot, A.; Van de Borne, M., "Analysing Impact of Scalability and Heterogeneity on the Performance of Federated Cloud Security," Trust, Security and Privacy in Computing and Communications (TrustCom), 2012 IEEE 11th International Conference on , vol., no., pp.1137,1142, 25-27 June 2012.

[22] Tianfield, H., "Security issues in cloud computing," Systems, Man, and Cybernetics (SMC), 2012 IEEE International Conference on , vol., no., pp.1082,1089, 1417 Oct. 2012

[23] Abuhussein, A.; Bedi, H.; Shiva, S., "Evaluating security and privacy in cloud computing services: A Stakeholder's perspective," Internet Technology And Secured Transactions, 2012 International Conference for, vol., no., pp.388,395, 10-12 Dec. 2012.

[24] Wentao Liu, "Research on cloud computing security problem and strategy," Consumer Electronics, Communications and Networks (CECNet), 2012 2nd International Conference on , vol., no., pp.1216,1219, 21 23 April 2012.

[25] Pant, N.; Parappa, S., "Seeding the cloud in a secured way: Cloud adoption and security compliance assessment methodologies," Software Engineering and Service Science (ICSESS), 2013 4th IEEE International Conference on, vol., no., pp.305, 308, 23-25 May 2013.

[26] Du meng," Data security in cloud computing", The 8th International Conference on Computer Science \& Education (ICCSE 2013) April 26-28, 2013. Colombo, Sri Lanka.

[27] Fan Yang; Li Pan; Muzhou Xiong; Shanyu Tang, "Establishment of Security Levels in Trusted Cloud Computing Platforms," Green Computing and Communications (GreenCom), 2013 IEEE and Internet of Things (iThings/CPSCom), IEEE International Conference on and IEEE Cyber, Physical and Social Computing, vol., no., pp.2119,2122, 20-23 Aug. 2013.

[28] Varadharajan, Vijay, and Udaya Tupakula. "TREASURE: Trust enhanced security for cloud environments." In Trust, Security and Privacy in Computing and Communications (TrustCom), 2012 IEEE 11th International Conference on, pp. 145-152. IEEE, 2012

[29] Astrova, Irina, Stella Gatziu Grivas, Marc Schaaf, Arne Koschel, Jan Bernhardt, Mark Dennis Kellermeier, Stefan Nitz, Francisco Carriedo Scher, and Michael Herr. "Security of a Public Cloud." In Innovative Mobile and Internet Services in Ubiquitous Computing (IMIS), 2012 Sixth International Conference on, pp. 564-569. IEEE, 2012.

[30] Hojabri, M., and K. V. Rao. "Innovation in cloud computing: Implementation of Kerberos version5in cloud computing in order to enhance the security issues." In Information Communication and Embedded Systems (ICICES), 2013 International Conference on, pp. 452456. IEEE, 2013.

[31] Xiao-hui, Liu, and Song Xin-fang. "Analysis on cloud computing and its security." In Computer Science \& Education (ICCSE), 2013 8th International Conference on, pp. 839-842. IEEE, 2013. 
[32] Benameur, Azzedine, Nathan S. Evans, and Matthew C. Elder. "Cloud resiliency and security via diversified replica execution and monitoring." In Resilient Control Systems (ISRCS), 2013 6th International Symposium on, pp. 150-155. IEEE, 2013.

[33] Khalil, Issa M., Abdallah Khreishah, Salah Bouktif, and Azeem Ahmad. "Security concerns in cloud computing." In Information Technology: New Generations (ITNG), 2013 Tenth International Conference on, pp. 411-416. IEEE, 2013.

[34] Yang, Ching-Nung, and Jia-Bin Lai. "Protecting Data Privacy and Security for Cloud Computing Based on Secret Sharing." In Biometrics and Security Technologies (ISBAST), 2013 International Symposium on, pp. 259-266. IEEE, 2013.

[35] Wang, Qian, Cong Wang, Kui Ren, Wenjing Lou, and Jin Li. "Enabling public auditability and data dynamics for storage security in cloud computing." Parallel and Distributed Systems, IEEE Transactions on 22, no. 5 (2011): 847-859.
[36] Ashutosh Kumar Dubey, Animesh Kumar Dubey,Vipul Agarwal, Yogeshver Khandagre, "Knowledge Discovery with a Subset-Superset Approach for Mining Heterogeneous Data with Dynamic Support",Conseg2012.

[37] Ashutosh K. Dubey, Ganesh Raj Kushwaha and Nishant Shrivastava,\|l Heterogeneous Data Mining Environment Based on DAM for Mobile Computing Environments, Information Technology and Mobile Communication Communications in Computer and Information Science, 2011, Springer LNCS.

[38] Sanjay Kumar Brahman, Brijesh Patel,'Data sharing and Management based on RC4 in User Cloud Environment", International Journal of Advanced Computer Research, Volume-3, Number-3, Issue-12, September-2013.

[39] Ajey Singh,Maneesh Shrivastava,"Overview of Security issues in Cloud Computing",International Journal of Advanced Computer Research (IJACR) ,Volume 2,Number 1,March 2012. 